\title{
Loss Prevention in Transportation to Ensure Product Quality: Insights from the Cargo Insurance Sector
}

\author{
Alexander C.H. Skorna ${ }^{1}$ and Elgar Fleisch ${ }^{1,2}$ \\ ${ }^{1}$ University of St.Gallen, Institute of Technology Management \\ ${ }^{2}$ ETH Zurich, Chair of Information Management \\ \{Alexander.Skorna,Elgar.Fleisch\}@unisg.ch, \\ efleisch@ethz.ch
}

\begin{abstract}
Transport operations are vulnerable to many types of risks due to an increasing dynamic and structural complexity of today's supply chain networks. Globally distributed sourcing and production lead to more transported goods in general but also to more high-value cargoes being shipped around the world. However, detailed information about the transport condition and integrity are not available in the end-to-end chain as transportation operations lack in full transparency. Therefore, this paper identifies causes and risks of cargo-related losses by an analysis of cargo insurance claims. Based on these results, appropriate preventive measures to improve the product quality during transportation are derived.
\end{abstract}

Keywords: Cargo insurance, claims analysis, loss prevention, quality improvement, supply chain risk management, transportation.

\section{Introduction}

Production and retail companies as shippers focus today on global distribution and local buying strategies to achieve comparatives advantages as well as to realize persistent growth. Shippers redesigned their transportation concepts to make themselves more flexible to customer needs and less vulnerable to market fluctuations as well as supply chain disruptions. Companies demand high levels of transport flexibility, customized transportation solutions, information systems integration, and short transit times at low costs. Therefore, today's transportation networks are highly complex and tightly-coupled systems that are vulnerable to many types of disturbances $[1,2]$. Transportation is thus mainly outsourced to logistics companies. On the one hand, this redesign results in a decreasing size of shipping units and higher transportation frequency to make the supply chains more agile. On the other hand, it leads to reduced dispensable safety stocks to follow state-of-the-art lean production programs [3].

Transportation is vulnerable to numerous types of risks such as loss or damages through temperature, humidity, tilt, and shock. Damages and losses mean problems for all supply chain actors, for instance due to business interruptions, lack of product availability and in consequence lost sales. Lately, new approaches of cargo insurance practices can be observed offering support and know-how to shippers for safeguarding their 
supply chains from these risks. These measures are preventive and aim at the improvement of transport processes as well as product quality, for instance, by fostering risk awareness among personnel employed in transportation and by the implementation of new devices to monitor and control transport conditions. Obviously, cargo insurance companies recognized claims prevention as an instrument to handle challenges and risks proactively [4]. A cargo insurance contract covers usually goods in-transit from the point of production to distribution and retail with all temporary storages in between. Thereby, the terms of contract (Incoterms) determine the liable actor in case a claim occurs in a transportation network.

\section{Related Work on Loss Prevention and Transportation}

To gain a deeper understanding of the potentially conflicting topics of insurance and prevention we review insurance research and insurance theory literature considering the prevention concept in general. Smith [5] has investigated the optimal insurance coverage due to the basic mechanisms of insurance. He distinguishes between 'over insurance', when the insurer overcompensates the insurance holder in terms of the occurred loss, and 'insurance selling', when the insurer pays not the full compensation but a proportion of it. We focus on the latter case, in which the insurance holder is taking a short position in its own loss. This is sensible because in this case risk prevention leads to balance the 'short position' [6,7].

In terms of cargo insurance the insurer usually compensates the shipper with the insured value of the affected goods when the claim is proven. But consequential losses due to e.g., business interruptions or out-of-stock situations (OOS) are not insured, which constitute the main motivation to implement prevention ensuring product quality in transportation from the shipper side, too.

Ehrlich and Becker [8] were the first to distinguish traditional 'market insurance' from two types of protection against damages and in particular loss. These are today typically referred to as 'loss reduction' and 'loss prevention' in insurance literature. Both represent engineering-types of traditional insurance alternatives which Ehrlich and Becker consider as 'self-insurance' and 'self-protection' respectively. Particularly, self-insurance lowers the financial severity of any occurred loss, while self-protection reduces the likelihood of loss [8,9]. An example of self-insurance is the installation of a sprinkler system to protect buildings or warehouses against fire damages. Accordingly, an example of self-protection is the equipment of doors with high security locks to hinder potential thieves from entering.

Impulses related to risk mitigation and prevention in transportation can be assigned to the supply chain risk management literature. It summarizes all strategies, measures, processes, and technologies to reduce supply chain risks [10-11]. As the authors explain, this is mainly achieved by (1) the avoidance of risks through proactive elimination of claims causes, (2) transferring risks to external parties through outsourcing or cargo insurance contracts, and (3) handling risks through setting intervention plans.

Identifying and assessing likely risks and their possible impact on operations across the supply chain is a complex challenge [12]. However, to properly assess vulnerabilities in a supply chain, firms should not only identify direct risks to their operations, but also the risks to all other entities as well as those risks caused by the 
transportation linkages between organizations [11]. Risk itself is an elusive construct that has a variety of different meanings, measurements and interpretations depending on the academic research field. Following the theoretical prevention concepts in insurance research outlined above, we use a hazard-focused interpretation common in risk management. Risk is defined as the probability of a given event multiplied by the severity of a negative business impact [13]. Sources of risk are losses e.g., theft, damage due to shock or tilt, spoilage of goods due to temperature or humidity as well as in-transit or customs delays [14]. Usually, this goes in line with quality drops affecting the transportation operations as well as the shippers' commitment to supply their customers. The causes of these risk sources can occur from inside and outside of a transportation network and vary greatly in their magnitude, attributes, and effects. Their consequences can be very heterogeneous, especially considering the often global scales of logistics operations [15,16] and networks [17] in which transportation is conducted.

Risk management related to the transportation chain includes processes which reduce the probability of occurrence and/or impact that detrimental supply chain events have on the specific company. Typical risk management strategies rely on closer partnerships among the transportation actors and risk sharing, e.g., outsourcing or consignment stocks [18]. Christopher and Lee [19] suggest improved end-to-end visibility as one key element in any strategy designed to mitigate supply chain risk. The authors argue that supply chain confidence increases with the quality of supply chain information.

The literature analysis reveals that first insights on quality improvements due to managing risks in supply chains exist. But, which particular impact a quality drop has on a transportation network remains still unclear. Moreover, the exact causes of claims and their impact on transportation processes are so far under researched. The following section provides first insights from the insurance sector.

\section{Empirical Analysis of Cargo Insurance Claims}

In order to impose proactive loss prevention measures, it is essential to have reliable information on the major problem areas in transportation. Therefore, we investigate original cargo claims reported to one of the largest cargo insurance companies in the Swiss insurance market over a time period of four years (2005 - 2008). The sample consisted in total of 7.284 claims. As claims reporting within cargo insurance usually is delayed by several months, insurance data have been generated out of the insurer's claims system in late 2009 and the analysis was conducted during 2010.

The average loss per incident was US\$ 19.265 indicating the great potential of possible quality improvement and loss prevention activities. The five largest incidents involved trucks as transportation mode and pharmaceuticals as affected goods. At this point it is important to note that the sample is not fully representative for the entire cargo insurance industry, as the customer portfolio is focused on the typical Swiss industries as pharmaceutical, chemical, and machinery as well as banks. Still, it provides some valuable insights for the identification of the current problem areas in transportation. 
The analysis follows two different perspectives. (1) The insurance view focuses on the effective claims handling costs per incident. This reveals areas for possible reductions in payments and resources as well as premium adjustments. (2) The client view focuses on the claims frequencies in order to identify possible areas to optimize transportation processes and product quality with cargo related loss prevention measures. The following two figures demonstrate these two perspectives and the related differences by analyzing causes and transportation mode relevant for claims incidents. As shown, frequent losses are not always simultaneously expensive ones.

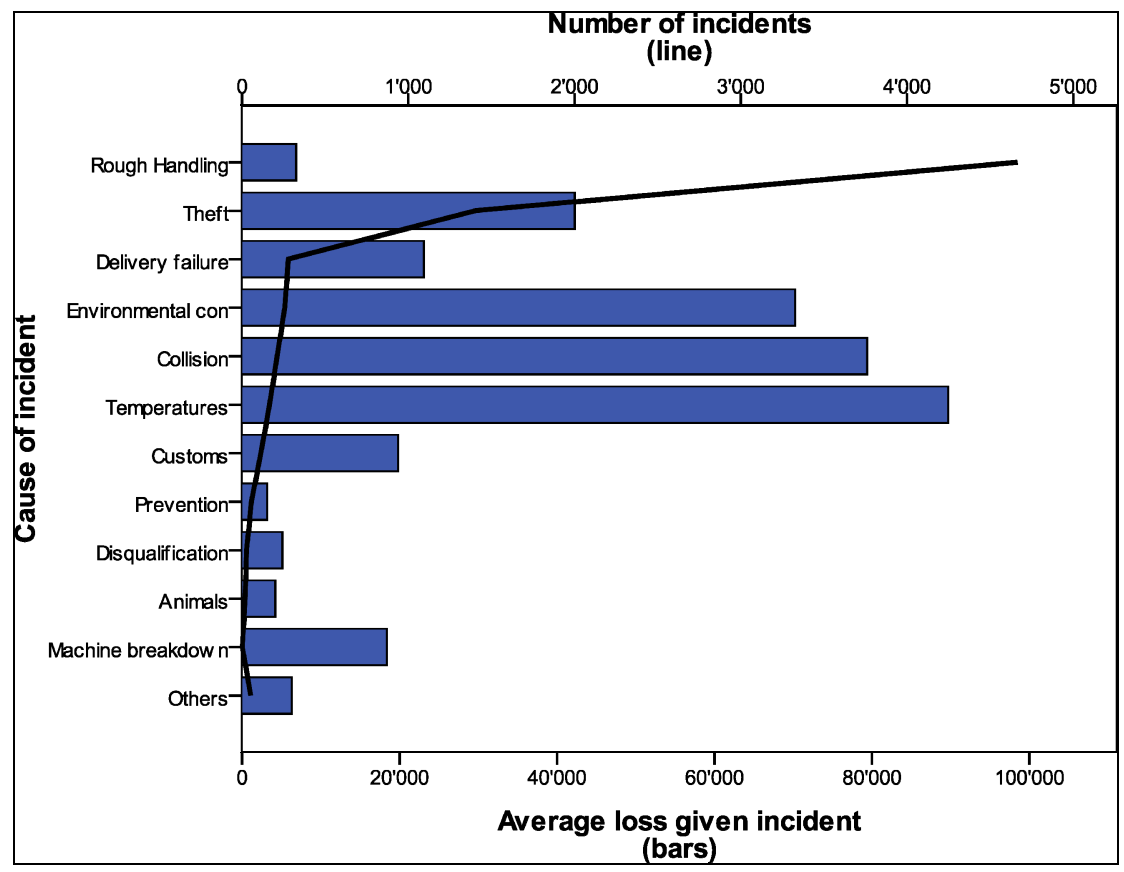

Fig. 1. Average loss given per incident and number of incidents by causes

We investigated the claims causes in detail and compared the average loss given incident and number of incidents shown in Figure 1. Overall more than 90 percent of the claims can be allocated to the following six causes: rough handling, theft (includes pilferage), delivery failures, environmental impact (includes condensation, moisture, fire, and oxidation), collisions, and temperature. More precisely, about 60 percent of the claims incidents are related to rough handling, but only 20 percent of the claims costs involve rough handling. Thus, the average loss given in terms of rough handling with US\$ 6.237 is relatively low.

Theft in particular of high value cargo is a serious threat to the profitability of companies. According to the claims statistic a third is spent on theft incidents, which account in terms of loss incidents for 20 percent of all claims. In this case we identified that especially high value air cargo shipments and full truck loads in Eastern Europe and the Russian Federation are a special target for organized crime. 
Moreover, and in comparison to Western Europe, the claims data sample indicates that cargo theft is also a major concern in North America.

The impact of temperature as the cause with the highest average loss given per incident involved primarily food, special chemicals, and pharmaceuticals. The restrictive handling advices and close temperature corridors, in which the shipments have to be distributed, makes cool chain transportations a complex task. Besides the main causes of loss rough handling and theft, the analysis also demonstrates a need for action for environmental and temperature related impacts.

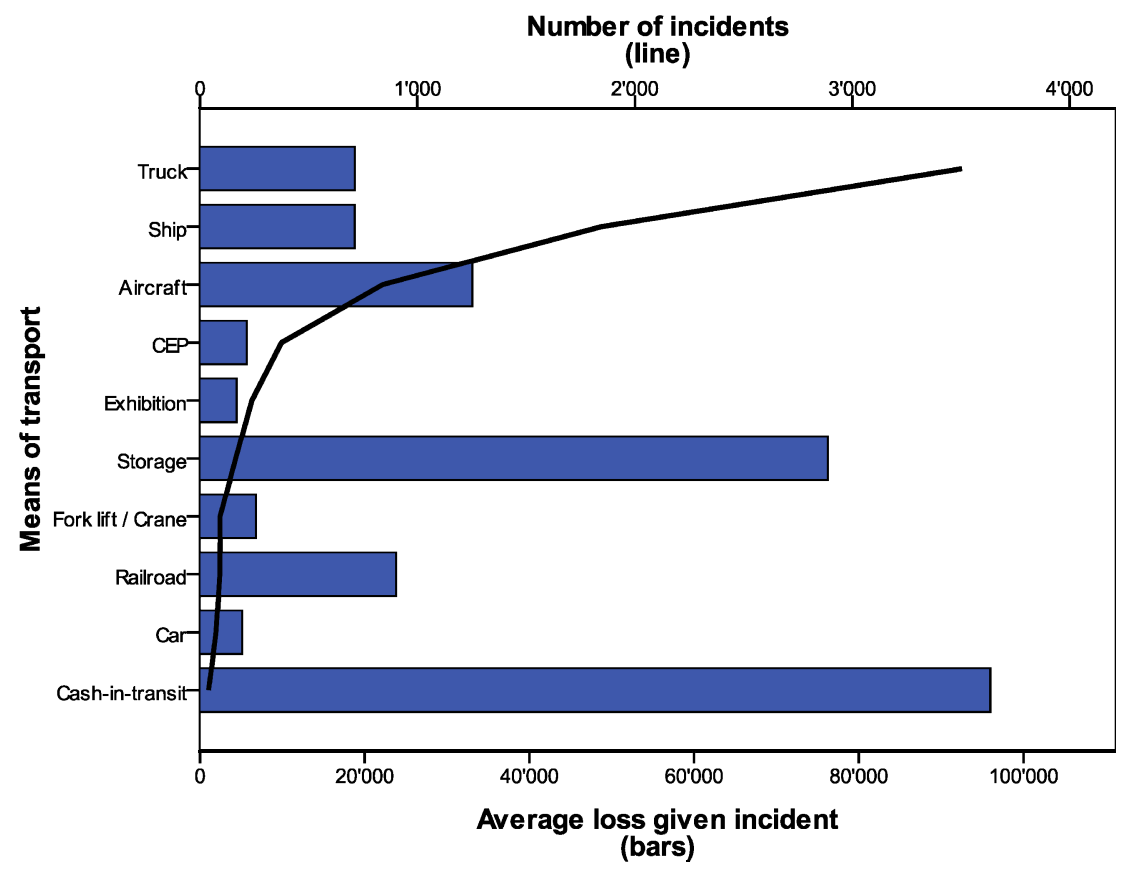

Fig. 2. Average loss given per incident and number of incidents by means of transportation

Extending the view of claims causes with the detailed analysis of the transportation mode Figure 2 shows that the main incidents occur in road transportation, sea as well as air freight. Hereby, it is remarkable that the average loss given incidents for truck and ship are about identical, while it is distinctly higher in case of air cargo. Imports and exports due to trade volumes in Europe are dominated by sea (72\%/ 73\%), but according to the trade value we see an increase of air cargo shipments which account for $23 \%$ (import) and 29\% (export) [20]. Air cargo shipments focus on high value cargo such as consumer electronics, spare parts, pharmaceutical, and chemical products which also explains this shift in terms of average loss given.

The high average loss at storage is particularly tightened by the impact of environmental conditions, while changes in temperatures pose a significant threat to transportation, too. Remarkable is the extreme average loss related to cash-in-transit. These rare events are related to secure transportation and theft cases and a particular problem for the cargo insurance industry in general. Insurance companies have to 
hold funds available when insuring these 'big loss' risks in the form of financial reserves which are not eligible for investment purposes. This has a comparably high impact on the investment strategy of an insurance company and makes cargo insurance a complex niche market due to the ever possible big loss threat.

According to the above considerations, we derive suitable areas for quality improvement and claims prevention measures. In terms of claims frequency these are related to rough handling and theft as well as to the main transportation modes truck, sea, air, and its related transportation concepts. Due to the high average loss given we particularly focus on theft and high value shipments which are often also affected by environmental and temperature conditions.

In the following section we provide useful loss preventive measures to improve product quality and avoiding losses during transportation.

\section{Measures to Improve Product Quality and Prevent Cargo Losses}

In general, the installation of a supply chain wide risk management is sophisticated. The more supply chain actors need to be integrated into risk management and the more risk situation, risk bearing ability, and risk management approaches differ from each other, the higher the implementation complexity. We distinguish technologyoriented and organizational measures, which both are suitable to prevent cargo losses and in parallel retain product quality as well as the retail shelf live.

Supply chains with lesser turnovers and direct deliveries have advantages in terms of successful operational process improvements. Thus, the choice of transportation routes so that the smallest possible amount of turnovers is necessary is a first obvious step. Henceforth, the choice or change in the transportation company because of their higher transportation quality or better damages and losses record in comparison to the existing one may be considered. The reduction of the transportation time e.g., by express deliveries or air freight reduces the exposure of the goods to loss risks. The implementation of special packaging concepts e.g., air cushions or foam pads increases the goods resilience to shock and drop events. Logistics companies so far only rely on mandatory trainings for their personal related to freight securing as well as handling dangerous and sensitive goods. Several authors mention the poor training level in these operations $[11,21,22]$.

The problem of above mentioned organizational measures is their poor transparency. Shippers can hardly control if the requested and paid special handling of goods complies with the actual operating procedures. Due to standardization efforts and decreasing prices for electronic parts, localization and condition monitoring has become a widely common service proceeding to even make risk monitoring and controlling autonomously possible. The assessment of changes in environmental conditions, e.g., temperature, humidity, and shock is a most important task for risk monitoring and controlling in transportation. This is also closely linked to detect quality losses by taking the changes in environmental conditions into account. According to Jedermann and Lang [23] only few sensor types are suitable for integration into transportation because of cost and energy consumption constraints. Temperature and humidity 
sensors consume the least energy as measures have to be taken only in intervals of several minutes. But shock and acceleration sensors have to operate permanently; otherwise they might miss a shock event.

However, cargo insurance companies begin to integrate prevention measures into their business and try to motivate clients implementing these accordingly. We developed together with a Swiss cargo insurance company a new technology-based prevention approach to be implemented at the insurance clients. The suggestions range from the implementation of very basic but inexpensive and easy to use prevention measures as indicators and data-loggers to compound sensor-telematic devices. All trigger the relevant risks derived in the previous section but achieve different levels of transparency and monitoring capabilities. Thus, basic indicators are in general more appropriate for frequent losses, telematic devices in turn are suitable for expensive losses with high loss amounts per incident. Shipping and handling monitors such as impact, tilt or temperature indicators are effective, highly regarded devices which can be considered as "low-tech" sensors. Once the goods are subjected to an impact exceeding a specified range, the indicator changes its color creating a permanent and immediate indication of mishandling. In contrast, telematic devices can be equipped with various sensors measuring i.e., temperature, humidity, and acceleration. The devices are capable for GPS localization and real-time data transmission through mobile and/or satellite networks. The devices are usually linked to web portals, which summarize the actual cargoes' status of integrity and transport conditions. Thus, damage and theft locations can be exactly pinpointed enabling fast corrective actions to be taken at any time. In between of indicators and telematic devices, data-loggers record the conditions during transportation which can be analyzed after the final delivery.

\section{Conclusion}

Integrated risk management in the insurance industry focuses so far on claims management and risk transfer through underwriting. Addressing risks in the supply chain requires the identification of risky events and vulnerabilities. The results shown in the claims analysis proofs the potential of risk preventive measures in transportation. These measures and related operative risk management principles expand the traditional risk management approach regarding loss prevention, consulting, implementation of risk controlling, and cooperation in the field of technology-supported early intervention to avoid or at least minimize losses. Risk prevention should consequently be based on continuous monitoring of the transport and warehousing conditions aiming to confine claims amounts. Implementing such technologies creates transparency and supports to identify and control cargo claims as well as vulnerabilities in transportation operations. In parallel, shippers, distributors, and retailers can improve packaging as well as adjusting the transportation processes according to their respective conditions and supply chain risks. This eventually leads to quality improvements of shipments as fewer claims in terms of cargo damage and losses occur. 


\section{References}

1. Wagner, S.M., Bode, C.: An empirical investigation into supply chain vulnerability. Journal of Purchasing and Supply Management 12(6), 301-312 (2007)

2. Blackhurst, J., Craighead, C., Elkins, D., Handfield, R.: An empirically derived agenda of critical research issues for managing supply-chain disruptions. International Journal of Production Research 43(19), 4067-4081 (2005)

3. Christopher, M., Towill, D.R.: Developing Market Specific Supply Chain Strategies. International Journal of Logistics Management 13(1), 1-14 (2002)

4. Skorna, A.C., Bode, C., Wagner, S.M.: Technology-Enabled Risk Management along the Transport Logistics Chain. In: Wagner, S.M., Bode, C. (eds.) Managing Risk and Security, pp. 197-220. Haupt, Berne (2009)

5. Smith, V.: Optimal Insurance Coverage. Journal of Political Economic 68, 68-77 (1968)

6. Gollier, C.: The Comparative Statistics of Changes in Risk Revisited. Journal of Economic Theory 66, 522-536 (2004)

7. Schlesinger, H., Venezian, E.: Insurance markets with loss-prevention activity: profits, market structure, and consumer welfare. Rand Journal of Economics 17(2), 227-238 (1986)

8. Ehrlich, I., Becker, G.S.: Market Insurance, Self-Insurance, and Self-Protection. Journal of Political Economy 80(4), 623-648 (1979)

9. Schlesinger, H.: The Theory of Insurance Demand. In: Dionne, G. (ed.) Handbook of Insurance. Springer, Berlin (2000)

10. Christopher, M., Peck, H.: Building the resilient supply chain. International Journal of Logistics Management 15(2), 1-13 (2004)

11. Jüttner, U.: Supply chain risk management - Understanding the business requirements from a practitioner perspective. International Journal of Logistics Management 16(1), 120-141 (2005)

12. Pfohl, H.-C., Köhler, H., Thomas, D.: State of the art in supply chain risk management research: empirical and conceptual findings and a roadmap for the implementation. Logistics Research 2, 33-44 (2010)

13. March, J.G., Shapira, Z.: Managerial perspectives on risk and risk taking. Management Science 33(11), 1404-1418 (1987)

14. Peleg-Gillai, B., Bhat, G., Sept, L.: Innovators in Supply Chain Security: Better Security Drives Business Value. Manufacturing Institute, Washington, DC (2006)

15. Manuj, I., Mentzer, J.T.: Global Supply Chain Risk Management. Journal of Business Logistics 29(1), 133-155 (2008)

16. Manuj, I., Mentzer, J.T.: Global supply chain risk management strategies. International Journal of Physical Distribution \& Logistics Management 33(3), 192-223 (2008)

17. Harland, C., Brenchley, R., Walker, H.: Risk in supply networks. Journal of Purchasing \& Supply Management 9, 51-62 (2003)

18. Zsidisin, G.A., Ellram, L.: An agency theory investigation of supply chain risk management. Journal of Supply Chain Management 39(3), 15-27 (2003)

19. Christopher, M., Lee, H.: Mitigating supply chain risk through improved confidence. International Journal of Physical Distribution \& Logistics Management 34(5), 388-396 (2003)

20. Pongas, E.: Extra EU-25 trade in goods by mode of transport. Statistics in focus 2/2006. European Communities, Luxembourg (2006) 
21. Finch, P.: Supply chain risk management. Supply Chain Management: An International Journal 9(2), 183-196 (2004)

22. Ritchie, B., Brindley, C.: Supply chain risk management and performance: A guiding framework for future development. International Journal of Operations \& Production Management 27(3), 303-322 (2007)

23. Jedermann, R., Lang, W.: The Benefits of Embedded Intelligence - Tasks and Applications for Ubiquitous Computing in Logistics. In: Floerkemeier, C., Langheinrich, M., Fleisch, E., Mattern, F., Sarma, S.E. (eds.) IOT 2008. LNCS, vol. 4952, pp. 105-122. Springer, Heidelberg (2008) 